\title{
Dormir, soñar, roncar, madrugar, tener pesadillas, sueños eróticos y perder el tiempo en Los Coloquios de Palatino y Pinciano de Juan Arce de Otálora
}

Recibido: 12/10/2020. Aceptado: 16/3/2021.

Divino Sueño, gloria de mortales,

Regalo dulce al mísero afligido

Fernando de Herrera

\section{Resumen}

Pocos son, en comparación con los dedicados a otros diálogos de la época, los trabajos que, desde que saliera a la luz en 1995 la primera edición de la obra, han concedido atención crítica a Los Coloquios de Palatino y Pinciano de Juan Arce de Otálora (1515/1520-1562). Este diálogo de carácter abierto y enciclopédico, nacido de un visible afán de totalidad, permite gracias a su heterogeneidad de contenidos numerosas vías para el enfoque de la crítica. La representación del sueño, el dormir, la vigilia o los ensueños, así como otros ejes temáticos que derivan de esta, constituye un punto de partida rico en matices y que permite múltiples interpretaciones. La materia onírica, que emana como tantas otras de la tesis central, vertebra una parte de las interlocuciones, culmina con ciertas jornadas, traduce los conocimientos de Arce sobre el tema y evidencia la curiosidad que los hombres del Renacimiento sintieron por los arcanos de la subjetividad humana, nada impropios de un género con alcances pedagógicos como el diálogo.

Palabras clave: Diálogo; Los Coloquios de Palatino y Pinciano; Juan Arce de Otálora; dormir; sueños.

Sleep, dream, snore, get up early, have nightmares, erotic dreams and mess around in Los Coloquios de Palatino y Pinciano by Juan Arce de Otálora

\author{
Abstract \\ While many scholarly works address mid-sixteenth-century dialogues, Juan Arce \\ de Otálora's (c. 1515/1520-1562) dialogue Los Coloquios de Palatino y Pinciano, firstly
}


edited in 1995, has been largely overlooked. Otálora's is a comprehensive and openminded dialogue, which provides a global vision and, thanks to the heterogeneity of its contents, allows a myriad of possibilities for critical focus. Themes such as dream representation, sleeping, vigil, or reveries, as well as other correlated thematic issues, become a nuanced rich starting point that provides multiple interpretations. Springing from the central thesis, oneiric material holds a part of the interlocutions, culminates in certain sessions, translates Arce's knowledge on the subject, and shows the curiosity of the men from the Renaissance on the mysteries of human subjectivity, characteristic of a genre with a pedagogical scope like the dialogue.

Keywords: Dialogue; Los Coloquios de Palatino y Pinciano; Juan Arce de Otálora; sleep; dreams.

De entre toda la maraña de obras que nos brinda el prolífico género del diálogo en el Renacimiento son Los coloquios de Palatino y Pinciano, del jurista vallisoletano Juan Arce de Otálora, una de las piezas de más innegable interés, extensión y complejidad, tanto en su marco como en su contenido. ${ }^{1}$ Para nuestras letras auriseculares constituye un verdadero filón bibliográfico que gracias a su azarosa edición y, sobre todo, a la gavilla de contenidos y temas de magnitud enciclopédica que lo vertebran, sigue ofreciendo un abanico enorme de posibilidades al estudioso que ante sus «pretensiones de totalidad $»^{2}$ decida aventurarse. El ingente volumen de páginas, editado por José Luis Ocasar Ariza tras un desmerecido olvido de cuatrocientos años, ya avala y justifica, per se, cualquier acercamiento a alguno de los pasajes de este diálogo. Como vislumbró Vian Herrero en fechas tempranas, ahondar en los pormenores de los Coloquios resulta en todo punto lícito y engarza con una labor de recuperación:

Lectura imprescindible para cualquier especialista en la literatura áurea, no debe pasar desapercibido en el panorama editorial de nuestros clásicos [...] Se trata de un clásico recuperado, uno de especial riqueza, que puede hacer reflexionar sobre el "canon", al menos, de los diálogos renacentistas, y que sin duda abre el camino a multitud de trabajos y monografías sobre todos los secretos y atractivos que encierra en sus páginas. (1997: 498-499)

Sea como fuere, las líneas anteriores deberían ser estímulo más que suficiente para acometer la revisión de los Coloquios o de algunos de los puntos que, entre su fértil varietas, despuntan. Pero sorprende que, solo pasados veinticinco años desde el pistoletazo de salida que supuso la edición final de más de 1400 páginas, aflore la duda de si ha menguado, o no, aquel creciente interés que, a juicio de Vian, iba a envolver a la obra después de un tan aparatoso confinamiento. Y es que, o bien a causa de unos contenidos misceláneos que rozan lo abrumador (Quero, 2018), o bien porque la colosal diversidad del corpus dialogal renacentista dificulta habitualmente la discriminación de obras específicas y la especialización en algunos de sus aspectos, a veces pareciera superfluo para la crítica irrumpir en los recovecos de la conversación que mantienen durante diecisiete jornadas Palatino y Pinciano. Pero precisamente es la amplificatio y la pluralidad de circunlocuciones en torno a la tesis central (Qui addit scientiam, addit laborem, Eclesiastés, I, 18) lo que permite, a los protagonistas de un lado, disertar sobre una vasta cantidad de cuestiones equidistantes del epicentro

1 Para el género dialogal durante el Renacimiento remitimos a los trabajos de Gómez (1988 y 200o) y Ferreras (2002). Un sucinto repaso de los primeros acercamientos a Los Coloquios de Palatino y Pinciano en Nicolás Antonio, Bataillon o Eugenio Asensio figura en Ocasar Ariza (2008: 11-13). Tampoco puede ignorarse la tesis de Norine Patricia O'Connor (1952) y las dos obras posteriores de Ma Isabel Lorca (1997 y 2004), amén de la edición de la obra (1995) y posterior estudio (2008) realizados por Ocasar Ariza. Huelga decir que, si se aborda la figura de Arce, prima la parquedad bibliográfica: tal es así que en Ocasar Ariza (2008: 273-283) solo una quincena de un total de más de 250 entradas bibliográficas hace mención explícita al autor, su vida, obra o algunos aspectos concretos de los Coloquios. En otro orden de cosas, consúltense Madrigal (2008), Rodríguez López-Vázquez (2010) y Calero (2011).

2 Expresión que extraemos del estudio introductorio de Ocasar Ariza al segundo volumen de su edición de la obra, por la que citaremos de aquí en adelante, señalando el número de la jornada y la estancia en romanos y el de la página en arábigos (Arce de Otálora, 1995: XVI). 
del debate y que imprimen a la obra, sin rayar en lo farragoso, un sello de abierta heterogeneidad (Ocasar Ariza, 2008: 85) y, a la crítica, de otro lado, ponderar con proporcional denuedo algunos de los vericuetos sensiblemente desatendidos dentro de los Coloquios.

Esta calibrada elongación y dilatación del thema es lo que justifica, de seguro, el número de abordajes a los muchos tramos de la obra. Pero el lector también requiere de la sagaz capacidad de Arce para saber poner fin, cuando la densidad lo demande, al devenir de la conversación. La calculada consecución del silencio garantiza la atención lectora, que precisa del mismo descanso que los facundos protagonistas. Claro está, al silencio absoluto solo se llega en la iglesia (Ocasar Ariza, 2001: 5-6), cuando declinan las jornadas (Ocasar Ariza, 2008: 57) o el teatro del sueño, que aristotélicamente sigue interconectando los procesos psicofisiológicos, ${ }^{3}$ cobra total protagonismo, embarga los sentidos de los dos interlocutores y suspende un tiempo narrativo a las puertas de su ocaso. Dormir y soñar operan en tanto que oportunos mecanismos diegéticos a los que Arce regresa, al inicio o final de múltiples jornadas, para mantener la credibilidad y rebajar la tónica aparentemente inagotable de la conversación. Así las cosas, la representación de aspectos onirológicos ${ }^{4}$ no es un campo infructuoso para quien dedique atención crítica al diálogo de Arce, máxime si nos adherimos de forma preliminar a ciertas aseveraciones de Monge Carretero:

Los sueños recogidos en los textos dependen de diversas tradiciones literarias, según el género al que se adscriban, pero no tienen directa vinculación con las especulaciones teóricas sobre el tema [...]. Al describir los sueños de los textos castellanos conforme al sistema que ofrecen los estudios teóricos, clásicos y medievales, al pretender proyectar cualquier clasificación rígida sobre ellos (la buscada oposición sueño/visión) se empobrece el punto de vista del estudioso, ya que es característico de estas narraciones el no atenerse a un esquema cerrado y puede acabar limitando el análisis solventar las numerosísimas contradicciones que se producen por imponer tal método (2001: 419).

A estas vicisitudes críticas súmanse otras ambigüedades que llamaremos inherentes al vocablo "sueño» en nuestra lengua y que emergen, aunque sea efímeramente, siempre que se quiere acotar el tema onírico en los Coloquios. ${ }^{5}$ Para solventarlas se hacen de inexcusable incidencia las acepciones, de cuño aristotélico, que de voces como «soñar», «dormir» o «pesadilla» registra, sin ir más lejos, el Tesoro de Covarrubias. ${ }^{6}$ Necesaria es la aclaración apriorística de las antedichas si queremos parar mientes en los Coloquios, obra donde el contenido de los puntuales sueños referidos por Palatino o Pinciano viene auspiciado por el efecto que los quehaceres diurnos o la francachela, en ocasiones pantagruélica, imprimen al final de numerosas jornadas. No merece la pena, sin embargo, explayarnos más en tales asertos, consabidas como son, en primer lugar, la teoría de los «hypóloipoi kinēseis», 7 y en segundo, la relación estrechísima entre los procesos digestivos, el ascenso de vapores y el sueño; ${ }^{8}$ pero

3 Para este punto, Cox Miller (2002: 64), y para el estudio de los sueños en el mundo clásico véanse, además del libro de Cox Miller ya citado, los trabajos de Harris (2009), Pérez Cortés (2017) o las páginas que García-Monge Carretero, en su estudio introductorio al Tratado del dormir de Lope de Barrientos, dedicara a las fuentes clásicas del tema (2001: 100-174), como ya hiciera Sabat de Rivers años atrás (1977).

4 Usamos el vocablo en el sentido que le otorgara Darío del Corno (1969). Vid., para el término, ciertas palabras de Elisa Ruiz García en su introducción al libro de Artemidoro (1989: 20-21).

5 Vid., la primera nota al pie insertada por La Croce y Pajares para su edición del De somnio et vigilia de Aristóteles (1987: 257). Para otro repaso de estas confusiones semánticas y un conato de clasificación en "sueños ficticios" o "visionarios", remitimos a Avilés (1981: 33-36). De la dialéctica generada entre sueño/visión tampoco se olvidan Le Goff (1983: 282-288) y Acebrón Ruiz (2003: 204-210).

6 Véanse todas ellas en Sebastián de Covarrubias Orozco (1611: 140v, 178v-179r, 221r).

7 Véanse, para este aspecto, los Parva Naturalia (1987: 299).

8 Recuérdese, entre los Tratados Hipocráticos, el libro cuarto del Perì diaít s (1986: 105-116), así como los Parva Naturalia del estagirita (1987: 268-274) o las líneas que a la digestión y el sueño dedican el Tratado del dormir (2001: 
sí, dejar por sentado el influjo perentorio que en determinadas experiencias oníricas tienen causas de lo más definidas, como, verbigratia, cuando Palatino cena carne de liebre (carne de proverbial ligereza) y se ve, en sueños, llevado en volandas.

Si la gula y los manjares son motor generador del rumbo que toman ciertos sueños (entroncando con la medicina y filosofía natural previas a Aristóteles), ${ }^{9}$ del mismo modo la pereza o la acedia, ${ }^{10}$ generadas por el sometimiento al otium y a unas distracciones mundanas que aminoran la perseverancia espiritual, ${ }^{11}$ son agentes por medio de los cuales cristaliza el descanso o se sueñan según qué contenidos, siempre a tenor de los derroteros que la diurna plática haya tomado. Cuando repican las campanas y los nicodemitas estudiantes (Ocasar Ariza, 2008: 164-192) asisten a misa, el remanso se oblitera y, las más de las veces, Palatino y Pinciano madrugan solo para proseguir con las chanzas en un nuevo marco espacial: la iglesia. ${ }^{12}$ De modo que solo la misa, el largo camino o la solicitud con que, mientras se extiende este, se materializa el intercambio verbal, son los móviles que libran a Palatino y Pinciano de la vagancia o la procrastinación. El descanso, en el marco de los Coloquios, no solo da lugar a varios excursos, sino que es una necesidad fisiológica experimentada, sentida por unos estudiantes a quienes vence el sueño y a quienes cuesta madrugar.

Palatino, el más dado a la abulia y menos a las labores, nos dice que «no hay cosa más contraria al sueño que el cuidado» (I, III, 162), ${ }^{13}$ siendo la "pereza» y la "ociosidad» más provechosas en «cuerpo y alma» (I, III, 164) o a la hora de regresar con mayor resiliencia a los estragos del camino. Pinciano indica que el mucho dormir es condición «de ánimos remisos y complexiones flojas y pesadas» (I, III, 164); pero el canonista, no menos ladino, alega que solo madrugan aquellos inquietos que nunca concilian un sueño placentero (I, III, 164). ${ }^{14}$ Para Pinciano, que renglones más tarde apoya su disertación en el enjundioso Somnium Scipionis contenido en el sexto libro de la República de Cicerón, la propensión al despreocupado dormir de Palatino se debe a los humores «flegmáticos» que imperan en su joven compañero, ${ }^{15}$ quien haciendo caso omiso sentencia que «el dormir es cosa natural y necesaria para pasar la vida» (I, III, 165) y que, así como madruga el labrador, duerme hasta tarde el señor (I, III, 166). ${ }^{16}$ La trapisonda sobre el mucho o poco dormir, como vemos, ocupa más de un ostensible rato en las interlocuciones de ambos protagonistas y solo se salda cuando Pinciano,

5-10) o la tesis doctoral de Acebrón Ruiz (2003: 67-74).

9 De ahí las innumerables imprecaciones teológicas contra la excesiva fruición en algunas viandas o el vino. Leemos en el capítulo LXVIII de la traducción al castellano hecha por Gonzalo de Ocaña de los Diálogos atribuidos a San Gregorio que el "finchamiento o vasiamiento del vientre» es la primera causa, entre las seis sistematizadas, de las imágenes producidas durante los sueños (2013: 323).

10 Vid., Peretó Rivas (2010). También habla de la evolución de la acedia al pecado de la pereza, desde la patrística a la escolástica, Monge Carretero en su introducción a Barrientos (2001: 317-327).

11 No se olvide el encono con que autores y obras de la época, y más aún los ámbitos teologales o médicos, escrutan los perjuicios de la inactividad, la vagancia o el mucho dormir. Revísese lo recopilado por Mexía en la Silva, I, XXXII, «En que se contienen muchos loores y excelencias del trabajo y los bienes que se siguen dél; y también los daños y males que causa la ociosidad..." (1989: 446-458).

12 De ahí que, en la jornada décima, reconozca el mismo Palatino: "Somos tan ruines los hombres que el sermón de hoy, porque llegaba a una hora, se nos hacía largo y no le podíamos sufrir, y habemos estado aquí tres horas diciendo desatinos sin cansarnos ni recibir pesadumbre» (II, X, 855).

13 "Cosa es de lástima el poco caso que se hace en el mundo de perder el tiempo, siendo la cosa más preciosa que Dios nos dio y la más propia» (II, X, 856).

14 No es el caso, sin lugar a duda, de Palatino, personaje nada "diligente y madrugador»: (II, XVII, 1391), (II, X, 801, 855856), (II, XI, 871, 882-883, 966), (II, XIV, 1089). Claro está, su constante cansancio viene motivado por el arduo camino, si bien, como leemos en la cuestión 318 de El porqué de todas las cosas (1668) de Andrés Ferrer de Valdecebro, "no descansa bien quien no se cansa bien" (2007: 199).

15 Así lo cree, entre muchos otros, Antonio de Torquemada en su Jardín de flores curiosas: «Los coléricos son más prestos en todo lo que se offresce, y los flegmáticos más tardíos y perezosos» (1994: 659). Y así describía Alfonso Martínez de Toledo en el Arcipreste de Talavera a aquellos condicionados por la preponderancia humoral de la flema: "Son tibios, nin buenos para acá, nin malos para allá, synón a manera de perezosos e ningligentes; que tanto se les da por lo que va como por lo que viene; dormidores, pesados, más floxos que madera" (1984: 182).

16 Dice Pinciano en la jornada novena: «No se entiende que por estar en vuestra tierra habéis de hacer del señor y estaros en la cama, especialmente habiendo de ir de caza» (II, IX, 695). 
trayendo a colación ciertos axiomas médicos de gran envergadura por aquel entonces, zanja la disputa recomendando unas idóneas «seis horas» de sueño ${ }^{17}$ y esgrimiendo una nómina de célebres personajes (Filippo, Sansón, Ulises, Polifemo) que, por pegárseles las sábanas, sufrieron fatídicos percances (I, III, 173-174). Tampoco olvida el civilista ciertas admoniciones que las Sagradas Escrituras arrojan contra la holgazanería ( $P r$, 6:9, 20:13 y 26:4 o Eclo, 34: 6, 7), óbice para todo hombre que se considere de provecho (Acebrón Ruiz, 2003: 66), si bien Palatino -opciones más ingeniosas- prefiere dormir en el Parnaso, la Caballina o despertar, tras un plácido sueño, con la ciencia infusa, como sucedió a Hesíodo o Salomón (I, III, 213-214).

Deslindados los beneficios o perjuicios consustanciales al poco o mucho dormir, más adelante la disputa vira hacia otros derroteros con los que Palatino y Pinciano, aunque sea diseminadamente, glosan más puntos de la teoría onírica. Las curiosas disertaciones sobre el ronquido o las posiciones nocturnas a adoptar en el lecho, con las que Arce abre la jornada undécima, tienen su origen en un desvelo (excesivamente presto para Pinciano; inhumano para Palatino) a las dos de la mañana, horas antes de partir los dos amigos hacia Medina del Campo. Pinciano ha velado (la cursiva es nuestra) el cuerpo de Palatino durante dos horas -somnus mortis imago est: Cicerón, Tusc., 38, 92; de ahí velar- ${ }^{18}$ y recrimina al canonista el «roncar como lirón y silbar como serpiente» (II, XII, 872), lo cual vuelve a ser condición despreciable de hombres «flojos y descuidados». ${ }^{19}$ Más que atributo aparecido a la hora en que un haragán de la talla de Palatino, de progenie goliarda, «arrufianada y picaresca» (Ocasar Ariza, 2008: 130), se mete en el catre, el ronquido nocturno es propio de «cochino y perro y serpiente». Además, la etiología es clara: el ronquido se intensifica o evita en función del grado de apertura de la bocay según si se duerme, o no, de espaldas. ${ }^{20}$ Solo la respiración nasal y el dormir bocarriba (hacerlo del revés es «causa de venir los espíritus oprimidos y hacer aquel ruido en el camino», II, XI, 872) ${ }^{21}$ salvarán a Palatino de entrársele «una araña o culebra por la boca» o de encendérsele los riñones:

PALATINO-El roncar no lo tengo por tan gran falta como decís, antes es una señal de vida, porque el que duerme sin roncar no sabemos si está vivo o muerto sin tomarle el pulso. Y si es tacha, consuélome, que muchos varones señalados han tenido esta virtud roncativa: Escipión dicen que roncaba, y allá cuenta Juan Bocacio que le valió al otro la vida el roncar. (II, XI, 873)

17 Coincide en este punto Pinciano con los coetáneos consejos que el teólogo madrileño Francisco de Monzón da a los religiosos en sus admonitorios Avisos espirituales que enseñan cómo el sueño corporal sea provechoso al espíritu (Lisboa, loannes de Blavio de Colonia, 1563): "Que en un dia natural ay veinte y quatro horas; de las quales las seis o las ocho se emplean en dormir: y no es justo que de tal manera se gasten que del todo se pierdan sin sacar fruto espiritual dellas" (fol., 5v). Tales límites horarios explican la exultante alegría de Palatino cuando en la onceava jornada descansa nueve horas (II, XI, 967).

18 Vid., el capítulo octavo redactado por Monzón: "Adonde se dan ciertos avisos con que se desponga el hombre cristiano a dormir como haze para morir: por la grande semejanza que ay dela muerte y del sueño" (1563: 22V-27v). 19 Se observarán en los tratados hipocráticos, sin duda de notoria influencia en la medicina medieval y renacentista (Jordán Arroyo, 2001: 175-176), pocas referencias al fenómeno del ronquido, al margen de algunas citas que sí tienen que ver con casos de pacientes que adolecen de una condición "floja y descuidada": sobrepeso, problemas expectorantes, angina, pólipo nasal, etc. Galeno, a su vez, compara el sonido bronco que emiten los animales afectados en sus nervios intercostales o arterias carótidas, así como la respiración de las víctimas de apoplejía o "sueño profundo" (2002: 29, 378), con el ronquido. La apnea y su consecuente respiración acelerada son, para Galeno, comunes en aquellos cuyo estómago oprime el diafragma (1997: 289, 421). La detención de Arce en la etiología del fenómeno es más prolija que la registrada en el Diccionario de Autoridades (tomo V, 1737): "ruido tosco o bronco con el resueIlo, quando se duerme. Dixose por la figura Onomatopeya, o del Latino Rhonchiffare». Para las teorías oníricas de Hipócrates y Galeno, basten Díaz Regañón López (1975) y Gil Fernández (2004).

20 Sirvan indistintamente, ahora extrapoladas al contexto del ronquido, ciertas palabras del médico francés Laurent Joubert en su Tratado de la risa (1579). Porque igual de sencillo es entonces, durante la noche, roncar o "reír que hablar o caminar, acciones que el alma también lleva a cabo por medio de los instrumentos que sirven a la voluntad". Todavía más: los instrumentos que facilitan la risa en sueños (diafragma, pecho, pulmones, músculos de la mandíbula inferior, labios) son los mismos que ejercen sus funciones cuando ronca el individuo (Joubert, 2002: 156-158).

21 Así también deduce Mexía del que «duerme echado de espaldas <y> el rostro para arriba, porque el calor natural se derrama, y por eso enflaquesce la digestión y las superfluydades no pueden acudir a la boca ni vías orinarias, antes caen al pecho y garganta y causan muchas veces ahogamientos [y] perlesías y otras enfermedades" (1990: 277). También Andrés Ferrer de Valdecebro (2007: 169). 
El epítome acerca del «buen dormir» no finaliza aquí: Pinciano, repasadas las recomendaciones para evitar una obstrucción del sueño a causa de la apnea, advierte también, mucho más pudibundo que su compañero, sobre la necesidad de acostarse honestamente. ${ }^{22}$ Después enumera otros avisos que, a fuer de ineludibles para una digestión exitosa, traducen otro arsenal de conocimientos asumidos por Arce:

PINCIANO - El buen dormir ha de ser sobre el lado derecho el primer sueño, por que baje el manjar a la boca del estómago, y después sobre el izquierdo, por que caya el hígado encima y le dé calor y le ayude a digirir, según la doctrina de los médicos. Y a la mañana, cuando está hecha la digestión, se han de volver otra vez sobre el lado derecho, porque el bazo limpie el estómago. (II, XI, 873) $)^{23}$

La explicación demorada sobre ciertos puntos de la teoría del sueño, el dormir o la vigilia en que recalan los interlocutores después de acontecida cualquier experiencia onírica o, en otro orden de cosas, el sueño como fenómeno erigido en eje vertebrador de la narración de un "yo» ${ }^{24}$ son, grosso modo, una suerte de moneda corriente que acuñan polianteas, misceláneas, tratados, discursos, sátiras menipeas o diálogos de los siglos XVI y XVII, ora por prurito pedagógico, ora por cierta propensión al eclecticismo. ${ }^{25}$ Por lo que al diálogo concierne, Jacqueline Ferreras no vacila en conceder un epígrafe al mundo del sueño, pivotando sobre dos paradigmáticos ejemplos: el Sueño del Marqués de Mondéjar, contenido en el Libro de la anathomia del hombre (1551) de Montaña de Monserrate, y los Diálogos familiares de la agricultura cristiana (1589) de Fray Juan de Pineda, parejas muestras de un «interés renovado, en la época, por ese fenómeno tan común como desconcertante» (2004: 272-273). Para el hombre del Renacimiento, no solo ocupan los sueños una significativa parcela dentro del ignoto y misterioso terreno de la subjetividad humana, ${ }^{26}$ sino que configuran todo un campo que, a efectos prácticos, se sabe singular porque rezuma la triple herencia de una tradición filosófica, teológica y médica (Jordán Arroyo, 2001: 169-170). Esta variedad de implicaciones explica que una de las obras más leídas por Arce fuera la tantas veces editada, elogiada y traducida Silva de varia lección, la cual dedica varios de sus capítulos al sueño o a los productos de la imaginación (II, 8: 585-586 y III, 35: 273-278), como también sucede en el divulgadísimo Jardín de flores curiosas de Antonio de Torquemada, por lo que a los aspectos más demoníacos del sueño se refiere ${ }^{27} \mathrm{o}$ en otro seguido de diálogos que, por su menor trascendencia, podríamos llamar de segundo orden, tales como los Diálogos de philosophia natural y moral (1564) de Pedro de Mercado y los Coloquios (1568) de Baltasar de Collazos. ${ }^{28}$ Las referencias, si el espacio no lo impidiera, podrían reduplicarse considerablemente, pero solo queremos apuntar que, en su contexto literario, es plenamente entendible el interés que por la onirología pudiera manifestar Arce de Otálora. Como representante de muchas de aquellas obras impresas a la sazón cuyos devaneos con el atrayente mundo de los sueños son más que patentes, la singularidad del jurista radica en que no se conforma con teorizar acerca de la materia por medio de lugares comunes, sino en hacer del sueño, dentro del marco del diálogo, un acontecimiento de dimensiones realistas al que sucumben Palatino y Pinciano, quienes no solo hablan sobre dormir o soñar, sino que duermen o sueñan.

22 Consejos también visibles en Monzón (1563: 32r-34v).

23 Conocimientos que figuran casi idénticos en Monzón (1563: 32r).

24 Sobre este motivo tratan Gómez Trueba (1999: 13-25) y Acebrón Ruiz (2003: 260-272).

25 Como evidencia la obra de ambicioso título de Ferrer de Valdecebro, impresa en las postrimerías del Barroco y que todavía dedica su trigésimo capítulo (cuestiones 316-325) al sueño y otras cuestiones anejas, por el interés que el fenómeno aún despertaba (2007: 198-202).

26 "Cosa maravillosa — nos dice Palatino-y secreto grande es este de los sueños..." (II, X, 792).

27 Véase la miscelánea de Torquemada (1994: 675-678, 692, 733).

28 Las respectivas referencias se recogen en Sánchez Bellido (2013: 442-443) o en la colectánea Diálogos españoles del Renacimiento (2010: 736-740). 
Tan creciente es, en suma, la curiosidad por el fenómeno de los somnia como crecientes son, desde el púlpito y los tratados teologales, los exabruptos acerbos que contra los sueños y el sueño se dirigen. La mayor pérdida para el hombre -nos espeta Monzón en su prólogo- «es la que se pasa con ociosidad, y con no tener más cuenta que con el vientre, y con el sueño» (1563: 1r). Y es que, solo evitando dormirse, y manteniéndose despierto -advierte a su vez Pinciano-, logra el hombre maravillarse con los innumerables bienes que el espectáculo de la creación divina le ofrece cada día (II, XI, 875). Gula y pereza (Acebrón Ruiz, 2003: 81) conforman un binomio de alcance demoníaco que no solo resulta objeto de iterativa animadversión para el ámbito eclesiástico y el ideario sermocinal del que se ocupa y que propala, sino que, como causas propiamente dichas, condicionan también el curso de los sueños y la óptica por antonomasia que, fundada en doctrinas paganas, paulinas o patrísticas, de ellos se tiene en la época. Tales diatribas, acendradas dentro de una «cultura del miedo», persuaden sobre los muchos beneficios de un descanso templado, virtuoso, ${ }^{29}$ y recuerdan machaconamente la vanidad de muchos sueños (Homero, Odisea, XIX, 247 ss., y Virgilio, Eneida, VI, 593 ss. ${ }^{30} \mathrm{o}$ la aureola diabólica que los envuelve, todo lo cual esclarece mejor el sentido de ciertas afirmaciones de Pinciano ("Creer en sueños nunca será bueno, porque es pecado y superstición», II, X, 791) o de Palatino («Yo creo en Dios y no en sueños», II, X, 791). Bajo el velo de lo onírico - predica el maestro Ciruelo en su Reprobación de las supersticiones y hechicerías-se esconden las inicuas intenciones del diablo, por lo que conviene:

Apartar de sí este cuidado de pensar en los sueños, porque como ellos pueden venir por muchas y diversas causas, la gente simple no acierta a saber por cuál causa vienen; y el diablo, como es sotil, presto podría engañar a los que se dan a esta vanidad. $(1977: 77)^{31}$

De ahí la escasa trascendencia que, para no incurrir en vanidades, Pinciano otorga a algunos de sus sueños. Así, antes del epílogo final, cuando nuestro interlocutor confiesa haberse acostado tarde, dormido mal y, lacónicamente, "soñado mil desvaríos» (II, XVII, 1355).

Quienes duermen sobre el corazón, y ya no hígado o riñones, sueñan nimiedades que, a veces, acongojan y compungen (II, XI, 873), y que despiertos rememoran con no menos perplejidad. A mayor pavor mueve una posada, a propósito del tema, cohabitada por trasgos, duendes y fantasmas como los que, al inicio de la jornada decimosexta, amedrentan a Palatino en forma de alucinación hipnopómpica: «Como me quebraron el sueño primero -se queja el canonista-y no vía luz, toda la noche he estado desasosegado, dormitando sin dormir ni estar despierto» ${ }^{32}$ (II, XVI, 1357), esto es, en una procelosa duermevela que incentiva la aparición del phantasma o visum, aparición de la que, solamente al disiparse el estupor que a Palatino invade, ${ }^{33}$ se toma conciencia de su falsedad y de su nulidad mántica o reveladora. Aunque un tablado fantasmagórico semejante parezca obra del demonio, «ilusión o engaño con que él lo hace creer en sueños o en vigilia» (II, XVI, 1262), poco incrédula es la actitud de Palatino y Pinciano, quienes consideran las hablillas sobre trasgos y duendes fruto de un supersticioso paganismo y cuento propio de agoreros, antes del cual nunca está de más persignarse y recitar el evangelio de san Marcos (II, XVI, 1258)... ${ }^{34}$ Lo que

29 Se explaya sobre ello Mexía (1990: 274).

30 Véanse las siguientes páginas del clásico estudio de E. R. Dodds (2019: 99-126).

31También Monzón (1563: 9r-12v).

32 La ambigüedad semántica dormir/descansar también le ocasionó algún que otro ligero quebradero de cabeza a Arce de Otálora, cuando cribaba variantes estilísticas a propósito de una referencia al Apóstol Santiago, según descubre Ocasar Ariza cotejando los manuscritos existentes (2008: 91).

33 Esto es, al consumirse el humor que generaba la pesadilla o desparecer el íncubo o súcubo (Monzón, 1563: 28r).

34 Para muchos de los remedios contra el Maligno y las tentaciones que acechan al durmiente, vid., Acebrón Ruiz (2003: 18-49). 
impele a tales desasosiegos es, en conjunto, un vestido, paronomásticamente, más «pestilencial» que «penitencial» $y$, sobre todo, una cama mal compuesta, aunque esta debiera cifrar, para Pinciano, la auténtica austeridad:

Para un dulce sueño es suficiente el duro suelo [...] y si no, una yacija hecha de paja o un lecho de piedras escogidas o de madera sencilla. Pero en efecto se hacen preparar, con muchos esfuerzos y gastos durante largo tiempo, camas con patas de marfil en sus armazones y se hacen lechos para reclinarse adornados con perfectas madreperlas y variopintas conchas de tortuga incrustadas, algunos completamente de plata y de oro o de mosaicos, adornados con cubiertas de flores multicolores o bordados de oro, para la exhibición y la presunción, y no para el uso cotidiano (Filón de Alejandría, 1997: 139-140).

Para desdicha del canonista, ni un lecho en condiciones paupérrimas ni el haber mantenido toda la jornada anterior la mente ocupada en lucubraciones en ningún punto deshonestas mitigan sus deseos más sicalípticos. Tras flirtear con una dueña de «hábitos meretricios» la noche antes de llegar a Medina y alojados ambos estudiantes en Salamanca (II, XV, 1190), Palatino tiene un sueño que, si no libidinoso, por lo menos resulta sugerentemente lascivo. Sistematizada con este episodio una de las restantes facetas oníricas por tratar -la del sueño erótico- Arce logra, para mayor densidad argumental todavía, que gracias a ella Palatino madrugue tanto como Pinciano:

PALATINO-Hoy lo habemos hecho honradamente, que despertamos a la par. Bien parece que nos vamos acercando a Salamanca, que no podemos dormir las mañanas.

PINCIANO-No lo hace eso, sino el cuidado en que nos puso aquella dama de anoche, que no debéis de ver la hora en que volver a su buena conversación.

PALATINO-Dios me lo perdone, que ya la tenía olvidada. Ella nos es cargo lo que anoche la festejamos y servimos; sepamos en qué nos lo ha de pagar y cuándo, que toda esta noche no me he podido apartar de ella en sueños. (II, XV, 1185)

Música de sirenas en plena odisea veraniega, esta es la única ocasión en que unas tentaciones deshonestas distienden el ritmo serio de un viaje y disputa que hasta el momento habían cumplido, cada noche, con este precepto de Monzón:

Se debe de tener grande cuidado quando uno se recoge a dormir; como prevenga que durmiendo no tenga rebeliones dela carne, ni el demonio le incite sus malas inclinaciones naturales; para que en despertando no se halle alterado y con tentación que le de fatiga; o le ponga en peligro de perder su castidad (fol. 34 r). ${ }^{35}$

Y es que, a Palatino, ningún rezo oportunista del salterio le libra del yugo de la tentación, al menos en sueños:

Ay males que de su naturaleza tienen materia de deleyte, como son los actos venereos e obras carnales; por esto el demonio engaña a sus sequaces y familiares con el cevo de los actos carnales, por detenerlos más en su engaño; porque con las mujeres participa tomando cuerpo de varon y con los hombres tomando cuerpo de muger, segun que muchas vexes determinan los dotores como los demonios suelen ser incubos e subcubos (Fray Martín de Castañega [1529] 1994: 28). ${ }^{36}$

35 Para otra sarta de remedia, véase el Arcipreste de Talavera: "sy estando en la cama tal escalentamiento se viniere, salta della; non te aduermas en pensar, synón luego sal fuera, e, resfriado el cuerpo, luego dará logar la carne, o luego como viniera comiença a rezar e a dezyr a lo menos: Ego pecator confiteor Deo...» (1984: 71).

36 Vid., el clásico libro de Koning (1977) o ciertas páginas de Monge Carretero (2001: 312-319). No se olvide que el íncubo sería lo más parecido al epiált s del que, como forma de visum, hablan las tan resonantes categorías 
Pero súcubo, fantasía con polución inclusive, 37 ensoñación impúdica de estirpe grecorromana ${ }^{38}$ o, simplemente, sueño erótico, ${ }^{39}$ el caso es que, como ya corroboraba el Arcipreste de Talavera, "amor e luxuria privan al onbre del sueño; que non puede dormir como solýa nin debe, e, privado del sueño, toda la noche congoxando, congoxando, nunca reposa, e non reposando es privado de folgança» (Martínez de Toledo, 1984: 75), como bien acontece al estudiante con la meretriz. Pecando por su libre albedrío o no, la poca castidad que resta a nuestro hedonista interlocutor termina por resquebrajarse en este sueño (acaso hypnerotomachia) del que no consigue salir tan morigerado como antes Palatino. Además, el placer experimentado en esta «realización de deseos» que es el sueño debería pagarse a la dueña que facilita las lúbricas ensoñaciones, como hiciera Théonides egipcio con la cortesana Lamia tras el placer que esta le brindara en sueños (II, XV, 1185-1186), tal como refiere Arce en esta anécdota y como en otros casos análogos de erotismo onírico se observa (Alatorre, 2003: 153-179).

Por lo que no es menos cierto que, siendo como es un fenómeno bifronte, el sueño también puede ser fuente de inesperado regocijo. Prueba fehaciente de ello es el testimonio de Laurent Joubert en su Tratado de la risa (1579): «los adultos, soñando, recuerdan lo que han visto durante el día y eso les mueve un poco menos que las cosas presentes. Por eso, quienes son más dados e inclinados a la risa y los que se pasan el día riéndose desaforadamente, también se ríen de buena gana durmiendo» (Joubert, 2002: 158)..$^{40} \mathrm{El}$ sueño, según los residuos diurnos que en nosotros reposan o del humor reinante, y antes de que la vigilia la disipe o preserve, puede ser motivo de una exultante alegría. En cierto modo la experimenta Palatino - un sujeto a quien, alternadamente, los sueños amilanan o refocilan-, antes de desengañarse al inicio de la jornada décima:

PINCIANO-No es tan de mañana como pensáis, sino que hace nublado y debéis tener vos los ojos con niebla. Las siete ha dado; por eso, dejála pereza y vistámonos, que parece que aún estáis durmiendo y habláis entre sueños.

PALATINO-A fe que me despertastes de un sueño que me daba contentamiento, y era que me llevaban a Nuestra Señora de la Vega en hombros, sin bonete, con gran grito y regocijo porque había llevado una cátedra de medicina

PINCIANO-¡Gracioso sueño era ése! ¿Llevar cátedra de medicina os daba contentamiento? (II, X, 789)

Las bienaventuranzas académicas que refiere Palatino, recién emancipado de los influjos de Hipnos, son, antes bien, de abolengo ucrónico y universal. Verse laureado, catapultado por la Fama a causa de los méritos propios configura toda una experiencia onírica que, si alcanza la categoría de atemporal, es por la recurrencia de tales deseos de un tiempo a esta parte. Retrocediendo significativamente en los siglos, unos anhelos semejantes eran ya visibles en la obra de uno de los indudables precedentes entre toda la legión de soñadores de la Antigüedad -amén de hipocondríaco sin tregua-, Elio Aristides, quien, tras encomendarse a Asclepio, nos refería en su aretalogía:

macrobianas durante la Edad Media, y que el demonio, tome la forma que tome, muy pocas veces es descartado de tipologías oníricas como las de San Agustín o San Gregorio que tanta notoriedad alcanzaron a su vez.

37 Véanse Alatorre (2003: 44-45) y Acebrón (2003: 83-84).

38 Para el tema desde un enfoque más helénico, Gil Fernández (1985).

39 No se olvide el tradicional estudio de Maurer (1990).

40 "Todavía es contentamiento, ya que el hombre sueña, soñar cosas de regocijo y no tristes", nos dice Palatino (II, X, 791). 
Soñé que estaba junto al altar de Zeus Olimpio, el de mis padres. Se estaba celebrando una reunión pública al final de la mañana, y el heraldo sagrado, que se encontraba junto a la basa de la estatua del Dios, proclamaba mi nombre con todos sus atributos, como si me fueran a coronar en público de la misma forma que cuando en las asambleas decretamos una corona de oro; y añadía: "por sus discursos». Y lo confirmó con el añadido de otra proposición: «pues como orador es insuperable» (1999, V: 380$).{ }^{41}$

El denominador común de estos sueños (ora se trate de Aristides reconocido, al fin, tras sus frustrados escarceos como orador, ora de Palatino vitoreado por su cátedra en medicina) es el atisbo de vanagloria que de los dos se desprende, vanagloria suficientemente vapuleada, a propósito de José, por Filón de Alejandría en el De somniis, ${ }^{42}$ y que insatisfecha en las ideas latentes de entrambos sueños termina por cristalizar en el contenido manifiesto. ${ }^{43} \mathrm{~A}$ la misma tipología de sueños, en este caso denominados «visiones» concernientes «a las dignidades y magisterios», había concedido otro breve espacio Arnau de Vilanova. ${ }^{44}$ Por lo que termina poniéndose de relieve -regresando al sueño de Palatino- que la jactancia, dentro del plano onírico, es una suerte de "pecadillo» (no es lugar ahora para los requilorios de si en sueños se peca o no por libre albedrío) ${ }^{45}$ sobradamente conocido por la preceptiva, la tratadística y los autores que abordan el tema, «pecadillo» del que precisamente adolece el sueño que nuestro interlocutor experimenta sin tener en cuenta una ligera salvedad: Palatino va para canonista y no para médico..$^{46}$ Es esta permutación de las disciplinas la que pronto extraña a Pinciano, quien ejerce de onirocrítico por cercanía o para revelar a su compañero el valor nulo de tal enypnion 47 y esclarecer que la distorsión se debe a las conversaciones mantenidas el día previo (Acebrón, 2003: 372), y quien advierte que el germen de tal trueque (ensayemos, ante litteram, el decir freudiano) viene inducido por un «desplazamiento» de las ideas latentes en el contenido manifiesto del sueño: $4^{8}$

PINCIANO— Placerá a Dios que sea así, pero yo apostaré de adevinar por qué soñastes más que era la cátedra de medicina que de leyes ni cánones ni otra facultad.

PALATINO- ¿Por qué?

PINCIANO- Porque hablamos anoche en el médico deste lugar y en la medicina, $y$ disputamos a la cena si era buena la carne de liebre o no... (II, X, 795)

\footnotetext{
41 Para otros episodios de signo parecido, véanse los Discursos Sagrados (1999: 294-295, 419).

42 Dice Filón a propósito de José, que ha olvidado su insignificancia ante la grandeza de Dios: «Él, soñador e intérprete de sueños, pues era ambas cosas, toma la vanagloria como si fuera la más grande, radiante y provechosa posesión...” (1997: 136). A los sueños de José dedicó ocho discursos otro lector de Filón de Alejandría como fue Pedro Rodríguez de Monforte (1687: 76v-112v).

43 Casualmente, Freud concedió unas líneas al llamado "sueño de examen", que sensiblemente tiene algo que ver con el enypnion acerca de la titulación en Medicina que, por obra de las peroratas diurnas, asola a Palatino durante la noche a que nos venimos refiriendo (1973: 514-515).

44 Capítulo décimo de su De somniorum interpretatione (1975).

45 Barrientos (2001: 47-50) y Monzón (1563: 32r). Para más profundización en el binomio sueño-pecado en todas sus vertientes (oniromancia, lujuria y pereza), vid., los epígrafes introductorios (2001: 298-328) de Monge Carretero o las líneas que, en su tratado exegético De Genesis ad litteram (XII, 15) dedicara el santo de Hipona a los sueños deshonestos y el pecado.

46 De tales distorsiones ya se ocupaba Aristóteles (1987: 289).

47 Sabido es, a nivel profético, el valor nulo del griego enypnia o phantasma por contraposición a los reveladores óneiroi. Véase, aun teniendo en cuenta el desconocimiento que de esta obra imperara en tiempos de Arce, de no ser por una dedicatoria de la primera traducción al italiano [1542] para Diego Hurtado de Mendoza, el tratado de Artemidoro (1989: 72-83). También Macrobio mencionó la esterilidad presagiadora del insomnium en el Comentario al "Sueño de Escipión" de Cicerón (2006: 137).

48 Vid., para la "deformación onírica", el "desplazamiento", las «ideas latentes" y el "contenido manifiesto" las respectivas páginas que indicamos en Freud (1973: 429-446, 532-535, 655, 727).
} 
Nada de revelador tiene, pues, este sueño acontecido, si no cuando raya el alba, por lo menos en los aledaños de esta. ${ }^{49}$ Poco válidos le parecen a Pinciano los saberes, apuntalados en la oniromancia clásica, de que hace gala su compañero: «los sueños de la mañana son los que tienen más semejanza con la verdad y un secreto espíritu de profecía y revelación» (II, X, 790). Porque nunca llegarán, de no ser por un drástico giro de los acontecimientos, a buen puerto las ínfulas médicas de Palatino. Tan poca madera de profeta demuestra el canonista como mucha perspicacia Pinciano a la hora de dirimir tal confusionismo oniromántico y al elucidar que el comentado sueño solo es reliquia, ateniéndonos a los postulados del momento, ${ }^{50}$ resultante tras las conversaciones sobre los escalafones universitarios, distintos emolumentos o, en suma, la tesis central que han ocupado a los amigos durante todo el diálogo y, más concretamente, en la jornada precedente. En materia de sueños, por ende, no debieran considerarse los dislates algo inusual, y mucho menos insólito, si recordamos los senderos tan peregrinos por los que discurre la fantasía. Los sueños, «aunque algunas veces corresponden a los pensamientos y negocios en que el espíritu anda ocupado entre día, otras veces son tan extraños y alejados de lo que se trata y negocia, y $\tan$ fuera de todo propósito, que parece que el espíritu estuvo fuera de todo juicio» (II, X, 793). El jubiloso sueño de Palatino, que deviene infructuoso en un nivel profético, aúna estas dos antinómicas vertientes y posee, en última instancia, una explicación «moral» que muy bien se acopla a quienes, como el hombre de letras, como el dicharachero Palatino, tanto se empecinan en algunas logomaquias humanísticas durante el día que, llegada la noche, no logran apartarse de ellas:

Ha lugar en los hombres de negocios o de letras, que por la mucha atención que de día ponen en las cosas en que se ocupan, la fantasía del hombre está muy puesta en pensar de aquellas cosas. No solamente cuando vela, más aún durmiendo representa muchas de aquellas cosas y algunas veces ordenadamente, otras desordenadamente (Ciruelo, 1977: 76). ${ }^{51}$

Además de (1) consecuencia, quasi infalible, de las muchas distracciones diurnas que ensimisman a los estudiantes, o desviación (2), en tantos otros casos, en que incurre la imaginación de Palatino (II, X, 793-794), Arce sabe que los ensueños también pueden ser (3) indicios de un desorden presente o (4) señales de un acontecimiento futuro. Caso paradigmático del tercer motivo vendrían a ser los diagnósticos médicos que, desde Hipócrates o Galeno y en pos de las carencias o superabundancias humorales que corrompen al enfermo, se interesan por las experiencias oníricas del afectado; símil que ilustra las tantas veces erróneas predicciones futuras (caso cuarto) por mor de unas desatinadas «facultades fantásticas» son las equiparables visiones erráticas que del campo visual tienen los de vista estragada, o quienes se obstinan en discernir figuras en el agua turbia, el arcoíris o las nubes condensadas por el ábrego (II, X, 793)..$^{52}$

49 El alba, como recordaba Barrientos, es momento propicio para la incubación de sueños verdaderos (2001: 58). Recuérdese que, precisamente por despertarse de buena mañana y realmente aturdido, no sabe Quevedo si otorgarle o no valor verídico al Sueño de la muerte (1991: 404-405). Teoriza Palatino: "Llaman al sueño de la mañana sueño de la vida; y es el que mantiene y engorda» (II, XI, 875).

50 "Quando alguno se ocupa en buenos y sanctos pensamientos dispierto merece que le den señales y muestras de su merescimiento durmiendo (...) las reliquias que quedan de las cogitaciones y pensamientos que tienen despiertos los hombres son las phantasmas que quedan impressas en la memoria y en la fantasia" (Monzón, 1563: 5v).

51 Alrededor de una centuria más tarde, toda la República literaria soñada en su juventud por Saavedra Fajardo se cimenta -nunca mejor dicho- sobre el andamiaje de las cavilaciones que al autor han ensimismado durante las horas previas al sopor y el descanso, cavilaciones que levantan, por causalidad, toda la posterior visión arquitectónica (Saavedra Fajardo, 1985: 69). Así también unas cavilaciones, en este caso lectoras, son las que determinan parte del rumbo de El Sueño del Juicio Final o el Sueño de la muerte (1991: 91,312). Valdecebro dedica la cuestión 317 al sueño inducido por la lectura, como sucede en los Sueños de Quevedo (2007: 198). Para estos aspectos en Quevedo, Cervantes y la cueva de Montesinos, sirva de referencia Egido (1994: 146-152).

52 Aristóteles (1987: 283-291), San Agustín (De Genesis ad litteram, XXV, 52) o el mismo tratado de Lope de Barrientos (2001: 38) se detienen en algunos de estos paralelismos. 
Arce sabía que estas visiones del juicio dormido carecen de valor mántico o fundamento, se encorsetan en la categoría llamada enypnion/insomnium y figuran en las tipologías macrobianas o de Artemidoro que hemos reproducido (por menester bibliográfico, no por acogernos a taxonomías) $)^{53}$ en páginas anteriores; pero la destreza ilustradora de su pluma no reside en sus doctas exposiciones sino en los ejemplos con que las ribetea. Sueños premonitorios de Marco Tulio, Calpurnia o Simónides apostillan las que, sin estas añadiduras, serían trilladas lecciones fisiológicas que, llegados al final de la obra, habrían abarcado hasta el último de los vericuetos posibles: beneficios y perjuicios del dormir, falsedad o carácter verídico del ensueño y la trabazón de las supersticiones, los deseos eróticos y el demonio con el sueño y los durmientes. Pero la novedad de Arce y su diálogo estriba en la capacidad para superar los límites teoréticos y reproducir los lugares comunes en las noches y los días de Pinciano, diligente en madrugar, y Palatino, ducho en dormir. Además, el impoluto repertorio de sueños más o menos sibilinos y de soñadores insignes con que Arce orla sus disquisiciones es signo sintomático de la galería de tópicos sobre tal materia en que gustaron libar aquellos eruditos juristas del Renacimiento, tópicos que, en ocasiones, trascienden la mera superficialidad o la pedantería gratuita y desmantelan la suma considerable de devotas lecturas que harto tiempo debieron ocupar a un espíritu ávido e inquieto como el de Arce. Botón de muestra es el sueño, referido en los Coloquios, de los «dos amigos mancebos de Arcadia que llegaron a la ciudad de Megara» (II, X, 792), cuya fuente pudo indistintamente otear Arce en la obra de Cicerón, Valerio Máximo o Lope de Barrientos, y sueño que aparece de nuevo en la obra de Gerolamo Cardano, quien, pocos lustros después, redactaría en 1562 unos Sueños Sinesianos, pábulo tardío para una curiosidad tampoco con el correr del tiempo extinta por el mundo onírico. ${ }^{54}$

Cumplida la expectativa fundamental de estas páginas - devolver la atención crítica a uno de los aspectos de los Coloquios de Palatino y Pinciano-, resta decir que el de Arce por la onirología es, según se ha demostrado, un interés total. El sueño es, primero de todo, un resorte dialógico para convencer al lector del necesario y verosímil cansancio que vence a los protagonistas al final del camino y del día, amén de mecanismo idóneo con el que sellar las jornadas. Flaquezas, en segundo lugar, que aquejan a los desocupados estudiantes por el alejamiento del negotium urbano y el trasiego de los claustros universitarios que los meses no lectivos permiten, ${ }^{55}$ el descanso y el sueño se tornan en pretexto para múltiples disquisiciones teóricas. Como lugar común al que recurrentemente se vuelve en la diégesis, o subtema que irradia desde la tesis central debatida por los interlocutores, el sueño y el dormir adquieren un peso sustancial en los Coloquios de Palatino y Pinciano. El interés de Arce-concluyamos con esto-no solo compete a los aspectos más consabidos del sueño, el dormir o la vigilia, de larga y varia tradición, sino a otros más heteróclitos y atípicos, tales como la etiología y remedio del ronquido o las posturas que el durmiente debe adoptar para facilitar el transcurso digestivo. Tales motivos temáticos, extractados de todo un legado cultural al que Arce remite por la autoridad de la fuente y que Arce comparte con otras obras en aquel tiempo transidas por un mismo influjo clásico, eran motivo más que suficiente para

53 Queda por estudiar la tipología por la que se rige Arce, quien habla de cuatro tipos de "sueños verdaderos" y uno vano o fantástico (II, X, 793-794), lo cual suma un total de cinco categorías onirológicas cuya fuente podría encontrarse en Macrobio (2006: 136-137), el De Genesis ad litteram de San Agustín (XII) o Gregorio Magno (IV, 68). La misma clasificación impera en Ciruelo, (1977: 75-77), Monzón (1563: 42r-5or) o el posterior tratado de Rodríguez de Monforte (1687: 2v-2r).

54 De algunos de ellos tuvo extenso conocimiento Arce (Ocasar Ariza, 2008: 116). Según Monge Carretero, este sueño aparece por primera vez referido en el De divinatione, y no en el De natura deorum, de Ciceron (2001: 296). Nuestro autor pudo tener noticia de él gracias a Cicerón (1999: 94) o la excerpta de Valerio Máximo (2003: 124), si bien tal sueño reaparece en Barrientos (2001: 25) o Cardano (1999: 332-333). De este cuento en concreto, sus relaciones con el campo onírico, el dogma de la inmortalidad del alma u otras fuentes en las que pudo beber Arce para su inserción en los Coloquios se ocupa Ocasar Ariza (2019) en un trabajo de reciente publicación.

$55 \mathrm{Al}$ interesante aspecto de la risa, las burlas, los entretenimientos y las diversiones que frecuentemente salpimentaban la vida y los viajes de los universitarios del siglo XVI apunta el reciente trabajo de Alberto del Campo Tejedor (2019), quien precisamente toma los Coloquios de Arce como referencia y eje central de su trabajo. 
avivar la curiosidad del autor, pretexto más que suficiente para la exhibición amena de unos conocimientos teóricos y, por encima de todo, fuelle más que suficiente para que Arce de Otálora, gracias a esta faceta, mantenga viva -por mucho que los sueños se asemejen a la muerte- la llama pedagógica de un género como el diálogo, que ciertamente a los Coloquios del vallisoletano debe buena parte de su riqueza. 


\section{Q Bibliografía}

"Acebrón, J. (2003). La aventura nocturna: claves del sueño en la literatura castellana medieval y del siglo XVI. Lleida: Universidad de Lleida.

"Acebrón, J. (2004). Sueño y ensueños en la literatura castellana medieval y del siglo XVI. Cáceres: Universidad de Extremadura.

" Alatorre, A. (2003). El sueño erótico en la poesía española de los siglos de oro. México: Fondo de Cultura Económico.

»Arce de Otálora, J. de (1995) [¿1539-1560?]. Los Coloquios de Palatino y Pinciano. Edición de J. L. Ocasar Ariza. 2 vols. Madrid: Biblioteca Castro.

»Aristides, E. (1999). Discursos. Edición de J.M. Cortés Copete. 5 vols. Madrid: Gredos.

»Aristóteles (1987). Acerca de la generación y la corrupción/ Tratados breves de historia natural. Madrid: Gredos.

»Artemidoro (1989). La interpretación de los sueños. Edición de E. Ruíz García. Madrid: Gredos.

» Avilés, M. (1981). Sueños ficticios y lucha ideológica en el Siglo de Oro. Madrid: Editora Nacional.

»Calero, F. (2011). “Los Coloquios de Palatino y Pinciano y la palinodia de José Luis Madrigal”. Espéculo: Revista de Estudios Literarios, 47. En: http://webs.ucm.es/ info/especulo/numero47/palatino.html; obtenido el 14/09/2020.

»Campo Tejedor, A. del (2019). Burla Burlando. Las diversiones de los universitarios en el siglo XVI. Salamanca: Amarante.

»Cardano, G. (1999) [1562]. El libro de los sueños. Madrid: Asociación española de neuropsiquiatría.

»Castañega, M. de (1994) [1529]. Tratado de las supersticiones y hechizerias y de la posibilidad y remedio dellas. Edición de J. R. Muro Abad. Logroño: Instituto de Estudios Riojanos.

»Cicerón, M. T. (1999). Sobre la adivinación/Sobre el destino/Timeo. Edición de A. Escobar. Madrid: Gredos.

"Ciruelo, P. (1977) [1538]. Reprobación de las supersticiones y hechicerías. Barcelona: Glosa.

" Corno, D. del (1969). Graecorum de re onirocritica scriptorum reliquiae. MilanoVarese: Instituto editoriale cisalpino.

»Covarrubias Horozco, S. de (1611). Tesoro de la lengua castellana o española. Madrid: Luis Sánchez.

»Cox Miller, P. (2002). Los sueños en la Antigüedad tardía: estudios sobre el imaginario de una cultura. Madrid: Siruela.

" Díaz Regañón López,J. M.a (1975). “Sueño y ensueño en el Corpus Hippocraticum”. Cuadernos de investigación filológica, 1, 2, 19-34.

»Dodds, E. R. (2019). Los griegos y lo irracional. Madrid: Alianza.

"Egido, A. (1994). Cervantes y las puertas del sueño. Estudios sobre La Galatea, el Quijote y el Persiles. Barcelona: PPU. 
» Ferreras, J. (2002). Los diálogos humanísticos del siglo XVI en lengua castellana. Murcia: Universidad de Murcia.

"Ferrer de Valdecebro, A. (2007) [1668]. El porqué de todas las cosas. Edición de A. Bernat Vistarini y J. T. Cull. Palma de Mallorca: José J. de Olañeta.

» Filón de Alejandría (1997). Sobre los sueños/ Sobre José. Edición de S. Torallas Tovar. Madrid: Gredos.

» Freud, S. (1973) [1899]. La interpretación de los sueños. En: Freud, S., Obras Completas I. Madrid: Editorial Biblioteca Nueva, 343-754.

» Galeno (1997). Sobre la localización de las enfermedades. Madrid: Gredos.

» Galeno (2002). Procedimientos anatómicos, Libros I-IX. Madrid: Gredos.

» Gil Fernández, L. (2004). “La diagnosis onírica en Galeno”. CFC (G): Estudios griegos e indoeuropeos, 14, 139-154.

» Gil Fernández, L. (1985). “Procvl recedant somnia. Los ensueños eróticos en la antigüedad pagana y cristiana". En: Mitxelena, K. (ed.), Symbolae Lvdovico Mitxelena Septuagenario Oblatae. Vitoria: Instituto de Ciencias de la Antigüedad, 193-219.

" Gómez Trueba, T. (1999). El sueño literario en España: consolidación y desarrollo del género. Madrid: Cátedra.

» Gómez, J. (1988). El diálogo en el Renacimiento español. Madrid: Cátedra.

» Gómez, J. (2000). El diálogo renacentista. Madrid: Ediciones del Laberinto.

" Harris, W. V. (2009). Dreams and experience in classical antiquity. CambridgeMassachusetts-London: Harvard University Press.

» Hipócrates (1986). Tratados Hipocráticos III. Edición de C. García Gual. Madrid: Gredos.

» Jordán Arroyo, M.a (2001). "Francisco Monzón y "el buen dormir": la interpretación teológica de los sueños en la España del siglo XVI". Cuadernos de Historia Moderna, 26, 169-184.

» Joubert, L. (2002) [1579]. Tratado de la risa. Madrid: Asociación Española de Neuropsiquiatría.

» Koning, F. (1977). Íncubos y súcubos: el diablo y el sexo. Barcelona: Plaza \& Janés.

»Le Goff,J.(1983). “Los sueños en la cultura y la psicología colectiva del Occidente medieval”. En: Le Goff, J. (ed.), Tiempo, trabajo y cultura en el Occidente medieval. Madrid: Taurus, 282-288.

»Lorca, M.a I. (1997). El jurista Juan Arce de Otálora (s. XVI): Pensamiento y obra. Madrid: Fundación Elías de Tejada y Erasmo Pércopo.

"Lorca, M.a I. (2004). La nobleza en los comienzos del Estado Moderno. El pensamiento del jurista Juan Arce de Otálora, situado en la encrucijada del Medievo y la Modernidad. Madrid: Centro de Estudios Políticos y Constitucionales.

" Macrobio (2006). Comentario al "Sueño de Escipión" de Cicerón. Madrid: Gredos.

" Madrigal, J. L. (2008). “Notas sobre la autoría del Lazarillo”. Lemir, 12, 137-236.

»Martínez de Toledo, A. de (1984). Arcipreste de Talavera o Corbacho. Edición de J. González Muela. Madrid: Castalia. 
" Maurer, C. (1990). “Soñé que te... ¿Dirélo? El soneto del sueño erótico en los siglos XVI y XVII”. Edad de Oro, 9,149-167.

» Mercado, P. de (2010) [1564]. Diálogos de philosophia natural y moral. En: Vian Herrero, A. (coord.), Diálogos españoles del Renacimiento. Toledo: Editorial Almuzara, 583-809.

» Mexía, P. (1989). Silva de varia lección. Edición de A. Castro. 2 vols. Madrid: Cátedra.

»Monge Carretero, I. G. (2001). Estudio y edición crítica del «Tratado del dormir» de Lope de Barrientos, Tesis Doctoral, Universidad Complutense de Madrid.

»Monzón, F. de (1563). Avisos espirituales que enseñan cómo el sueño corporal sea provechoso al espíritu. Lisboa: Ioannes de Blavio de Colonia.

»Ocasar Ariza, J. L. (1992). "La tradición manuscrita de los Coloquios de Palatino y Pinciano de Juan de Arce de Otálora”. Criticón, 56, 81-85.

"Ocasar Ariza, J. L. (1996). “Un humanista del siglo XVI: Juan de Arce de Otálora”. En: Rafael de Pascual, F. et alii (coord.), Humanismo y Císter: Actas del I Congreso Nacional de Humanistas Españoles. León: Universidad de León, 379-387.

"Ocasar Ariza, J. L. (2001). “La fragua de la interlocución en un diálogo renacentista: los Coloquios de Palatino y Pinciano de Juan de Arce de Otálora”. Criticón, 81-82, 229-245.

»Ocasar Ariza, J. L. (2008). La lucha invisible: estudio genético-literario de los Coloquios de Palatino y Pinciano, de Juan de Arce de Otálora. Valladolid: Universidad de Valladolid.

» Ocasar Ariza, J. L. (2014). “La amistad dialógica en tiempos recios”. Studia Aurea, 8, 369-386.

»Ocasar Ariza, J. L. (2015). “La palabra exiliada. El cronotopo como expresión de ideología anticultural”. eHumanista, 29, 342-359.

"Ocasar Ariza, J. L. (2019). “El fantasma de Pomponazzi. Un apunte sobre literatura y heterodoxia en el Renacimiento". En: Baranda, C. y Ocasar, J.L. (eds.), Duelos textuales en tiempos de Reforma. Anejos de Criticón, Presses Universitaires du Midi (PUM). En: https://books.openedition.org/pumi/14653; obtenido el 20/07/2020.

"O'Connor, N. P. (1952). Juan Arce de Otalora, Coloquios de Palatino y Pinciano: an erasmian dialogue of the sixteenth century: $A$ critical analisis of the unpublished manuscript. Austin: Texas.

» Peretó Rivas, R. (2010). "El itinerario medieval de la acedia”. Intus Legere Historia, 4, 1, 33-48.

"Pérez Cortés, S. (2017). Soñar en la Antigüedad. Los soñadores y su experiencia. Barcelona: Anthropos.

"Quero, F. (2018). "Savoirs miscellanés et régimen dialogique dans les Coloquios de Palatino y Pinciano de Juan de Arce de Otálora”. E-Spania: Revue électronique d'études hispaniques médiévales, 29. En: https://journals.openedition. org/e-spania/27404; obtenido el 18/o9/2020.

»Quevedo, F. de (1991) [1627]. Los Sueños. Edición de I. Arellano. Madrid: Cátedra.

»Rodríguez de Monforte, P. (1687). Sueños mysteriosos de la escritura, en discursos sagrados, políticos, y morales. Madrid: Antonio Román.

»Rodríguez López-Vázquez, A. (2010). “Juan de Arce de Otálora y el Lazarillo de 
Tormes", Artifara, 10. En: http://www.cervantesvirtual.com/obra/juan-de-arcede-otalora-y-el-lazarilo-de-tormes-924079/; obtenido el 27/08/2020.

"Sabat de Rivers, G. (1977). El "sueño" de Sor Juana Inés de la Cruz. Tradiciones literarias y originalidad. London: Tamesis Books.

»Sáenz, J. (2013). Edición y estudio de la traducción castellana de los Diálogos atribuidos a Gregorio Magno realizada por Gonzalo de Ocaña (S. XV), Tesis Doctoral dirigida por el Dr. Jorge Fernández López, Universidad de La Rioja.

"San Agustín. Obras completas, exegéticas: Del Génesis a la letra. En: https:// www.augustinus.it/spagnolo/index.html; obtenido el 06/05/2020.

»Sánchez Bellido, S. (2013) [1568]. Estudio y edición de los Coloquios de Baltasar de Collazos, Tesis Doctoral dirigida por la Dra. Ana Vian Herrero, Universidad Complutense de Madrid.

» Saavedra Fajardo, D. de (1985). República literaria. Barcelona: Plaza \& Janés.

" Torquemada, A. de (1994). Obras completas I: Manual de escribientes, Coloquios Satíricos/Jardín de Flores curiosas. Madrid: Biblioteca Castro.

»Valerio Máximo (2003). Hechos y dichos memorables. 2 vols. Madrid: Gredos.

»Vian Herrero, A. (1997). “La recuperación de un clásico: Coloquios de Palatino y Pinciano de Juan de Arce de Otálora”. Bulletin Hispanique, 99, 2, 498-499.

»Vilanova, A. de (1975). De la interpretación de los sueños. Barcelona: Editorial Labor. 
